\title{
Política criminal de la nueva justicia penal (1999-2007)
}

\section{Resumen}

Luego de precisar el concepto de política criminal, el autor examina aquélla que fuera implementada por el Ministerio Público, en el marco de la nueva justicia penal, entre 1999 y 2007, periodo en el cual se desempeñara como Fiscal Nacional.

Palabras clave

política criminal, justicia penal, Ministerio Público.

${ }^{*}$ Ex Fiscal Nacional del Ministerio Público. Profesor de Derecho Procesal

\section{Definición o concepto de la "política criminal”.}

En primer término, hay que buscar una definición de lo que se entiende por política criminal y tomaremos las que indican nuestros tratadistas nacionales.

Eduardo Novoa sostiene que la política criminal no puede ser estimada como ciencia, sino que es el arte de conciliar la doctrina con los hechos y constituye el puente entre la teoría jurídica y la realidad social.

La política criminal debe basarse en: a) El aporte teórico-ideal del derecho penal, como el aporte causal explicativo de la criminología; b) Procurar la mayor eficacia en la lucha contra el delito; c) Abarcar tanto el aspecto preventivo como el represivo; d) Hacer la crítica de las leyes vigentes y proponer su reforma, y e) Ser un arte de las posibilidades legislativo-penales en un momento determinado.

En resumen, la adecuación de las normas jurídicas ideales a una realidad viva, con miras a una lucha eficiente contra el delito, constituye el papel de la política criminal. 
Sergio Politoff, J. Pierre Matus y María Cecilia Ramírez sostienen que el derecho penal como regulación aislada no puede bastarse a si mismo, sino que como parte de un conjunto (el sistema penal), que a su vez se integra en la "táctica política" del Estado para alcanzar los fines que éste se propone, y así como hay políticas de salud pública, políticas ambientales, políticas de transporte, políticas de educación, hay también políticas del Estado para mejorar la legislación penal y para elaborar criterios que deben tomarse en cuenta a la hora de tomar decisiones en el ámbito del derecho penal; en especial una política criminal debe resguardar que la capacidad del aparato de la justicia penal no se vea excedido.

A su vez el Profesor Garrido Montt, define a la P.Cr. diciendo que sus objetivos son el planteamiento de ideas o cambios a seguir frente a los comportamientos desviados (delitos) y para la creación o perfeccionamiento de la normativa penal. Citando a Roxin, la P.Cr. se ocupa de "la cuestión de cómo debe tratarse a las personas que atentan contra las reglas básicas de la convivencia social", sin que sea suficiente una política simplemente crítica y propositiva de reformas legales sino que debe vincularse con los fines generales de la legislación y de la institucionalidad.

Es decir, según entendemos, en todo Estado debe haber una preocupación permanente de los juristas y particularmente de las autoridades, para la elaboración de una política pública criminal dinámica que apunte a los progresos que son necesarios en la aplicación del sistema penal.

Hay numerosas tendencias, posiciones doctrinarias encontradas y evoluciones en torno a los postulados de una política criminal justa y eficiente y sobre si el derecho penal debe ser el mínimo o si puede ampliarse, considerando la sociedad actual de riesgos.

En la década del ' 80 y hasta el día de hoy, existen tratadistas que abogan por lo que ellos denominan "el derecho penal mínimo", que sanciona exclusivamente los delitos más lesivos o graves y que desconfían del legislador que permanentemente busca ampliar los tipos penales para solucionar los crecientes problemas de la sociedad moderna, a veces con una técnica muy imperfecta e insuficiente.

Según esta tesis, deben excluirse los delitos menos lesivos que denominan como de bagatela y también los ilícitos que afectan la marcha económica de un país o afectan la salud pública o el ambiente o los riesgos sociales, toda vez que esta ampliación del derecho penal es muy inconveniente desde el punto de vista de las garantías individuales y además pueden perfectamente ser abordados por la administración, sin saturar el sistema penal que de por sí es insuficiente para tratar de los delitos graves.

Podemos citar a los penalistas, entre ellos Cornelius Prittwitz, Hassemer y otros que forman la llamada Escuela de Frankfurt. Ellos valoran negativamente una flexibilización de los criterios dogmáticos de imputación y de las garantías político-criminales del derecho penal y el derecho procesal penal clásicos, fundándose en que la intervención penal del Estado debe respetar al máximo la esfera de libertad personal del individuo. 
Critican especialmente el fenómeno de la extensión del derecho penal a la protección social ante los nuevos riesgos, ya que en concepto de esta tesis no es una función que deba ser satisfecha por el derecho penal. También recelan de la tendencia legislativa de emplear masivamente los delitos de peligro abstracto y en general sostienen que fuera del derecho penal nuclear (homicidio, lesiones, delitos contra la libertad sexual, delitos contra el patrimonio, delitos contra el Estado, etc.), la intervención del derecho penal sería ilegítima porque afectaría la esfera de libertad de los ciudadanos, incompatible con la consideración del derecho penal como "última ratio" y que para otras conductas que integran el derecho penal accesorio es preferible buscar soluciones intermedias entre el derecho penal y el derecho administrativo.

Es importante subrayar que Prittwitz, que estuvo dos años en Chile, comisionado en el Ministerio de Justicia, por la Fundación GTZ en que el Gobierno alemán tiene participación mayoritaria, asesoró la preparación de la reforma procesal penal en nuestro país y luego desde Alemania donde nos recibió en el año 2000, ha seguido de cerca el nuevo proceso chileno. Esto lo digo porque me parece ver que alguna influencia pudo tener en el proyecto de C.P.P. y en la preparación de la reforma procesal penal.

También se advierte cierta adhesión a la teoría del derecho penal mínimo en algunas exposiciones de profesores chilenos de derecho penal y en particular de los representantes de la Defensoría Penal Pública, en sus alegaciones en los tribunales y en sus opiniones en seminarios.

Esta tesis se opone radicalmente a la teoría del "derecho penal del enemigo" que persigue la defensa del ciudadano y en general de la sociedad, frente a peligros crecientes de estos últimos años, tales como el terrorismo, los tráficos de personas, los ilícitos internacionales, las organizaciones criminales que se preparan para delinquir, etc., etc. Esta tendencia ha tenido su máxima expresión en las reacciones de diversos países occidentales, tales como EE.UU. y europeos, frente al terrorismo (caso de la guerra de Irak, sucesos del 11 de septiembre, terroristas presos en la Base de Guantánamo, etc.).

Este derecho penal del enemigo no lo consideraremos en el análisis de la política criminal porque atenta en contra de los derechos básicos de la persona y tiene un símil con la concepción de los regímenes totalitarios.

Frente a estas distintas y abiertamente opuestas teorías, hay un sinfín de teorías intermedias que buscan una mejor protección de la sociedad y de sus riesgos, sin desmedro del respeto de las garantías individuales.

Ahora bien, el problema y el consiguiente debate en Europa consiste básicamente en que la sociedad liberal del siglo XIX que da origen a los Códigos Penales tradicionales, ha cambiado fuertemente en el siglo XX y en lo que va del siglo XXI, para llegar a la llamada sociedad de riesgos.

El derecho penal está en expansión como consecuencia de la nueva "sociedad del riesgo" en que vivimos y se cita al efecto la aparición de nuevos riesgos como el medio 
ambiente, la flora y fauna, el carácter transnacional o global de la delincuencia, la aparición de delitos de trascendencia internacional y el incremento de la sensación subjetiva de la inseguridad de los ciudadanos. Los individuos de la nueva sociedad post industrial demandan al Estado más seguridad y más protección, aspectos que no fueron considerados por el derecho penal liberal clásico. Según esta tesis, la expansión del derecho penal es inevitable y que no puede entenderse que esta expansión importe una merma de las garantías inherentes al Estado de Derecho.

Otro aspecto interesante de aquellos que defienden la expansión del derecho penal es que "los ilícitos que se considera que no deben incluirse en el derecho penal nuclear son conductas que solo pueden ser cometidas por quienes tienen poder y/o dinero. Solo los ciudadanos con capacidad económica y/o en situación de poder, pueden cometer delitos fiscales, delitos societarios, delitos contra el medio ambiente, delitos de corrupción.

También sostiene esta escuela que "la legitimidad de la intervención penal no debe decidirse exclusivamente a partir de los principios de subsidiariedad y ultima ratio, sino que también debe atenderse al principio de fragmentariedad, en cuanto deberán castigarse las conductas especialmente graves en relación con cualquier bien jurídicorelevante, aunque sean ilícitos civiles o mercantiles, al igual que aquellas que solo tienen impacto en los bienes jurídico-penales individuales tan "clásicos" como pueden ser la intimidad, el honor o la propiedad".

"En definitiva, en el contexto de la denominada "sociedad del riesgo", no puede dudarse del afianzamiento de este "nuevo" Derecho Penal, pese a las críticas referidas. Este ámbito del Derecho penal, lejos de una pretendida instrumentalización de control formal, persigue proteger la confianza de los ciudadanos en el funcionamiento del sistema y a partir del ello asegurar el libre desarrollo de la personalidad. En este "nuevo" Derecho penal confluyen, por consiguiente, el nuevo sistema de Estado social, con un nuevo sistema de valores, y el nuevo sistema de Estado liberal, en el contexto de la sociedad tecnológica post-industrial. Esta evolución científica, tecnológica, socio-económica y, paralelamente, del pensamiento político, ha llevado al legislador a proteger penalmente nuevos bienes jurídicos, a la doctrina y jurisprudencia a reinterpretar el sentido de algunos bienes jurídico-penales tradicionales y, por último, al sistema judicial a perseguir efectivamente y a condenar por la comisión de un "delito de peligro" sin esperar a que se haya producido un resultado lesivo para la vida, la salud o la propiedad.

Las críticas a la falta de efectividad y a la poca o nula aplicación judicial, siendo en alguna medida ciertas, no sirven para deslegitimar la intervención penal frente a estos riesgos. Ello es así por diversas razones, en primer lugar, en relación con la eficacia, porque no puede negarse que la intervención penal en ámbitos tan distintos como el tributario o el medio ambiente ha sido eficaz, lo que no excluye que pudiera serlo más y, sobre todo, mejor. Mejor porque es cierto que en estos delitos no siempre se están castigando penalmente las conductas más graves, lo que no es algo exclusivo de estos delitos pero que en ellos es especialmente criticable. Sin embargo, desde una perspec- 
tiva de prevención general negativa, su eficacia es innegable, por cuanto, mientras un "empresario" (abarcando con este término a los administradores, gerentes consejeros...) puede minimizar cualquier sanción, por elevada que sea, y contabilizarla como gastos $\mathrm{o} / \mathrm{y}$ repercutirla en el producto, es más difícil que asuma personalmente un proceso penal, cuanto más una condena.

Así mismo, tampoco puede menospreciarse su eficacia desde una perspectiva de prevención general positiva, por cuanto, su criticada naturaleza de Derecho penal simbólico sirve como reconocimiento de la importancia de los bienes protegidos. Siendo cierto que un precepto penal que solo tiene un valor simbólico debe rechazarse, no lo es menos que el significado simbólico es positivo cuando confluye con otras funciones, por cuanto, sirve al reconocimiento social de la importancia de ese concreto bien jurídico y con ello se produce una mayor sintonía entre las valoraciones sociales y las jurídicas. Por consiguiente, la función simbólica que tienen algunos de estos delitos contra bienes jurídicos supraindividuales no solo no es criticable sino que es necesaria, siempre y cuando ésta no sea la única función que cumplan.

Respecto de la mayor o menor eficacia, atendiendo a la nula o cuasi nula aplicación judicial, no pueden olvidarse dos factores esenciales al respecto. Primero que para la aplicación judicial de un nuevo delito no es suficiente con la creación de un nuevo precepto en el Código Penal, sino que son necesarios medios que permitan una investigación correcta de los hechos, en este sentido estaría la creación de Fiscalías anticorrupción o, actualmente, de Fiscalía en materia de seguridad en el trabajo. Segundo, que es necesario que los jueces conozcan, comprendan y sepan aplicar adecuadamente esos nuevos preceptos, respecto de los que se carece de una jurisprudencia consolidada. Al respecto habría que plantearse si no serían necesarios también Tribunales especializados, que no es lo mismo que Tribunales especiales, para conocer de determinadas materias fuertemente especializadas, como pueden ser las relativas al medio ambiente, societario, propiedad intelectual, propiedad industrial ... En definitiva, en la aplicación judicial o no de determinados delitos confluyen muchos aspectos y la inaplicación no deslegitima por sí misma esos delitos sino que debería obligar a analizar sus causas y solo en el caso de que se advirtiera de la ineficacia o imposibilidad absoluta de su aplicación se justificaría su desincriminación.

En síntesis, para no alargar este debate doctrinario, nos parece muy sugestivo el concepto acuñado en la fórmula "no hay libertad sin seguridad" y que entiende que la circunstancia de que el derecho penal no sea mínimo, esto es que no se encuentre circunscrito a la protección de los bienes jurídicos de naturaleza estrictamente personal, no importa una intromisión ilegítima del Estado en la esfera de libertad del individuo y que justamente esta libertad solo puede ser asegurada mediante la prevención penal de los nuevos riesgos, tesis que defienden algunos penalistas españoles y alemanes. 


\section{- Algunos debates surgidos en Chile que pudieran reflejar la influencia de las distintas tesis de política criminal.}

Tentativamente, daremos algunos ejemplos que reflejan las distintas posiciones sobre política criminal y que se advierte en algunos debates judiciales como también en distintos seminarios de la reforma procesal penal.

Podrá recordarse el caso del fallecimiento de numerosas personas en el puente Tinguiririca, en que el fiscal formalizó por cuasidelito de homicidio a los directivos de la empresa de buses, que no le permitían a los choferes tener el suficiente descanso para manejar adecuadamente y no dormirse en el volante.

El fiscal del caso solicitó un informe en derecho al Profesor dn. Héctor Hernández, acerca de la responsabilidad penal de los directivos de la empresa, informe en que se responde afirmativamente porque existe la responsabilidad por los riesgos que importa mantener una flota de buses en que viajan pasajeros a los cuales se les debe garantizar un viaje seguro, lo que era imposible si los choferes no tenían jornadas de descanso adecuadas.

El asunto se resolvió mediante una salida alternativa, entiendo que fue un acuerdo reparatorio suscrito por la mayoría de las víctimas, pero los imputados no reconocieron su responsabilidad penal.

Otro caso que pudiera tener alguna relación con esta problemática, es el caso del médico que operó a una mujer en una clínica privada, sin los elementos mínimos de seguridad que evitaran el riesgo de la paciente que murió, y en que los tribunales, entiendo que por primera vez, condenaron por homicidio por dolo eventual y no cuasidelito de homicidio que habría sido lo habitual. Es decir, si un profesional ejerce como cirujano, debe conocer los riesgos de su intervención y si no los asume, debe responsabilizarse de las consecuencias por el dolo eventual en su conducta, ya que existiendo un riesgo evidente no se preocupó de tomar ninguna medida para evitarlo.

Nos parece ver también que en las discusiones planteadas al Tribunal Constitucional por la defensa de varios imputados para declarar la inconstitucionalidad de normas legales tales como la que sanciona el microtráfico hay una influencia de fondo de la discusión de las políticas criminales. En efecto, se ha alegado una posible inconstitucionalidad en cuanto existe una intromisión excesiva en la esfera privada de los individuos, sin perjuicio de otras alegaciones jurídicas.

Cada vez que se implementan nuevos delitos relativos a la seguridad social o a la regulación de conductas monopólicas o que vulneran las reglas sobre comportamiento en los mercados de valores o cuando se aprovechan las informaciones privilegiadas, delitos de muy difícil pesquisa, siempre se escuchan alegaciones en contra de la excesiva amplitud que está tomando el derecho penal frente a las garantías individuales, es decir, existe una crítica a la excesiva intromisión del Estado que a pretexto de la seguridad invade la libertad personal de los individuos. 
También existe un debate en Chile acerca de la naturaleza del nuevo delito de maltrato habitual dentro de la violencia intrafamiliar, que puede ser físico, sin que constituyan lesiones, o hasta psíquico.

Es probable que en el futuro también haya discusión en cuanto al delito de aumento patrimonial relevante de ciertas autoridades que deben declarar sus bienes. ¿Qué es un aumento relevante? ¿No habría sido mejor una sanción tributaria que una sanción penal?

También es corriente escuchar como argumento de la inutilidad de una intervención penal excesiva, de que se trata de delitos de difícil pesquisa en que suele fracasar la justicia, congestionando el sistema penal y utilizando recursos públicos que podrían estar mejor usados. La misma argumentación se utiliza cuando en las últimas leyes se han aumentado las atribuciones de los fiscales y de las policías, porque importan un gasto excesivo fiscal que no es necesario ya que el derecho penal debe cubrir solo las hipótesis graves y mínimas y no ampliarse en forma excesiva.

Otro aspecto en que también se denota una influencia de las tesis de política criminal, lo que también se da actualmente en Europa sobre si el derecho penal debe ser mínimo o si debe también asumir y sancionar los riesgos sociales, es la crítica académica muy fuerte, la que comparten algunos jueces de garantía, acerca del concepto de la seguridad de la sociedad como limitante de la libertad de los imputados durante el proceso, discusión que ya lleva muchos años y que no tiene señales de terminar.

La doctrina de los principales penalistas y procesalistas de la reforma considera que el concepto de seguridad de la sociedad es un resabio de los regímenes totalitarios y que solo reconocen como válida la limitación de la libertad en el peligro de fuga. La fórmula del antiguo C.P.P., Art. 363, que describía la seguridad de la sociedad por la existencia de antecedentes graves de que el imputado trataría de eludir la acción de la justicia o continuar su actividad delictiva era más apropiada que la actual fórmula del nuevo Código, porque incluía el peligro de fuga que frustraba la continuación en la acción delictiva.

Estas discusiones se dieron mucho en la tramitación de la ley 20.253 sobre agenda corta antidelincuencia, pero también en la anterior ley 20.074 que modificó los Códigos Penal y Procesal Penal, en que hubo una intensa discusión doctrinaria en que la casi totalidad de los profesores invitados impugnaron diversas normas procesales penales por estimarlas inconstitucionales y atentatorias en contra de los derechos fundamentales de los imputados, aun cuando las votaciones respectivas en la Sala del Senado fueron abrumadoras en el sentido opuesto al sustentado por los académicos.

Hace poco me tocó asistir a un seminario sobre la víctima en el nuevo proceso penal y en que uno de los participantes, destacado profesor de Derecho Penal, sostuvo que había una deformación en aquellos políticos que estaban obsesionados con la defensa de la víctima y que proponían un servicio jurídico especial que la representara, porque el conflicto penal se daba únicamente entre el Estado y el imputado, sin que la víctima 
pudiera ańadir nada nuevo a este conflicto que le era ajeno, y ańadió textualmente: "Todo esto sucede por la deformación que ha significado la tesis de la seguridad ciudadana, altamente violatoria de los derechos fundamentales de los individuos". (Se exhibieron estadísticas de las fiscalías de Santiago para demostrar que el aporte de los abogados de las víctimas era casi nulo).

Hay que observar que las tesis de los penalistas y doctrinarios sobre el derecho penal mínimo tienen un solo problema insalvable, cual es que no son compartidos por la ciudadanía común y por los personeros políticos, tanto de Gobierno como de oposición, que urgen buscar nuevas fórmulas penales, a veces mediante técnicas muy imperfectas, para enfrentar novedosos y peligrosos riesgos de la sociedad moderna.

Con esta introducción, entro a explicar cuál habría sido la política criminal de la nueva justicia penal en estos últimos ocho años (1999-2007) que comprende el período en que me desempeñé como Fiscal Nacional.

Reconocemos que es difícil dar una respuesta porque la interrogante supone que realmente haya existido una determinada política criminal y no varias, durante estos ocho ańos de implementación de la reforma, porque al parecer han existido importantes variaciones en la política criminal durante este período.

Para estos efectos debemos distinguir varias fases o períodos en una evolución de diez ańos, aproximadamente.

Al respecto, debemos distinguir cuáles habrían sido los propósitos del Ministerio de Justicia que presidió la reforma desde su preparación en 1994 en adelante, hasta la aprobación de los proyectos básicos de la reforma en 1999 y 2000. Luego habría que examinar lo que han sido algunas modificaciones legales, que no han sido pocas durante estos ocho ańos, para ver si ha existido un cambio en la política criminal. Y finalmente habría que revisar el panorama legislativo general durante estos últimos ańos para ver si se confirma la tesis de la ampliación del derecho penal y el rechazo del derecho penal mínimo.

Además, tendremos que referirnos a si existe definición clara de cuál o cuáles son las autoridades encargadas de proponer y definir las políticas criminales que necesita el país.

Nos atrevemos a sostener que salvo en la primera parte de esta evolución, en que claramente se advierte la influencia de la doctrina del derecho penal mínimo, en las etapas posteriores, aunque de una manera inorgánica, prima ampliamente la tesis opuesta de la ampliación del derecho penal para proteger riesgos que no estaban cubiertos en la aplicación liberal y tradicional del derecho penal. 


\section{A) Periodo entre 1994 y el año 2000, bajo el patrocinio del Ministerio de Justicia de esa época, en que se aprueban las leyes fundamentales de la nueva justicia criminal, vale decir, el nuevo C.P.P., la Ley del Ministerio Público, los nuevos Tribunales de Garantía y Orales que se crean para la reforma y la Ley de la Defensoría Penal Pública.}

A partir de 1994, se empieza a preparar un anteproyecto de nuevo Código Procesal Penal en que participan destacados miembros del foro y de la cátedra, que culmina con la presentación del proyecto de C.P.P. el 09.06.95.

En el Mensaje del nuevo C.P.P. hay referencias a conceptos de la persecución penal que son demostrativos de una política criminal que busca limitar la intervención del Estado a aquellos delitos graves o lesivos y a ahuyentar la persecución de los delitos menos lesivos.

Por ej. se sostiene que el sistema penal debe ser reformado más allá de la reforma procesal penal porque "supone modificar nuestros criterios de criminalización primaria, introduciendo principios como los de lesividad y última ratio" y para ello está el nuevo Ministerio Público "que debe asumir la función de ordenar la utilización de los recursos represivos del sistema conforme a criterios generales, conocidos y legitimados por medio de la discusión pública y frente a organismos representativos de la comunidad”.

Y más adelante insiste en que "como ocurre en todos los sectores del Estado, los recursos para la persecución penal son inevitablemente escasos y, por ese motivo, no toda forma de conducta desviada puede ser reprimida”, justificándose de esta manera la rentabilidad del nuevo sistema acusatorio.

También el Mensaje critica que buena parte de la represión penal se ha traducido en la persecución de criminalidad de bagatela cometida por los sectores más vulnerables de la población y que por ello esta persecución es discriminatoria e ineficiente, correspondiendo al Ministerio Público, en base a criterios político-criminales explícitos, seleccionar la persecución hacia la criminalidad más lesiva.

Como producto de estas concepciones, se propusieron y aceptaron las salidas alternativas de la suspensión condicional del procedimiento y los acuerdos reparatorios, tratándose de la criminalidad menos lesiva. También, tratándose de delitos de menor entidad, se facultó al Ministerio Público para desestimar un caso en uso del principio de oportunidad. Por último, mediante los procedimientos simplificados y abreviados se posibilitó un juicio de resultado rápido, si se aceptaban por el imputado los hechos de la acusación o admitía responsabilidad en los hechos del requerimiento.

Nuestra opinión es que estas salidas son positivas si son bien aplicadas y no se omiten o desvían los requisitos legales que posibilitan su aplicación, por acuerdos entre fiscales y defensores.

Los porcentajes de estas salidas alternativas han ido en aumento en estos últimos años. No obstante, tratándose de las condiciones de las suspensiones así como las de 
los beneficios alternativos de la ley 18.216, su control es muy deficiente a todas luces y muchas veces no conducen a la reinserción social.

Haciéndose cargo de la situación anterior en que existe un notable déficit en el control y aprovechamiento de las medidas alternativas de la ley 18.216, recientemente el Ejecutivo envió al Congreso un proyecto (Boletín No 5838-07) que se está tratando con urgencia en la Comisión de Legislación de la Cámara.

En dicho proyecto se introducen mecanismos de control más eficiente y se proponen medidas concretas para favorecer la reinserción social de los delincuentes menores o de aquellos que hayan sido favorecidos con la ley 18.216, tales como la reparación del daño y el trabajo en beneficio de la comunidad. En cambio, se excluye la libertad vigilada respecto de ciertos delitos graves. Este proyecto, si se aprueba y si cuenta con el respaldo económico necesario, es una clara demostración de una política criminal tendiente a la reinserción social y económica de personas condenadas por delitos menores.

En el primitivo proyecto de C.P.P., aprobado, en su Art. 398, permitía la suspensión de la imposición de una condena tratándose de faltas y simples delitos, demostrándose que la política criminal en materia de suspensión de condenas era más amplia que la tradicional, para evitar la persecución de ilícitos menores, dejando sin efecto y demostrando que no era del interés del sistema que se condenara por faltas y por algunos simples delitos.

Sin embargo, en los primeros tiempos de la reforma hubo tal cantidad de suspensiones de condenas por simple delito, que incluso suspendían la remisión condicional o la aplicación de la ley 18.216 impuestas en la misma sentencia, que el legislador efectuó un cambio de la política criminal respectiva, suprimiéndose en la ley 20.074 las suspensiones de la condena de los simples delitos y volviendo al criterio del antiguo C.P.P. que sólo permitía la suspensión de las condenas por faltas (votación unánime).

También cabe recordar que en el primitivo C.P.P., el fiscal no podía solicitar la prisión preventiva para las faltas y que tampoco ello era posible tratándose de simples delitos cuya pena probable no fuera superior a los 540 días, pero estos criterios fueron modificados por la ley 19.789 del 2002 y luego por la ley 20.074 del 2005, demostrándose de esta forma una mayor severidad penal que se apartó de la finalidad político-criminal del primitivo C.P.P.

En cuanto a la política penal referida más bien a si son necesarias las modificaciones legales del C. Penal, la entonces Ministra de Justicia rechazó reiteradamente que se modificara la legislación penal, sea estableciendo nuevos tipos penales o endureciendo las penas existentes y siempre adujo que ello no era necesario porque con la reforma procesal penal la delincuencia iba a disminuir fuertemente y que era muy inconveniente estar legislando parcialmente en materias penales. Ańadió que en su oportunidad se propondría al país un nuevo Código Penal que fuera armónico con la nueva justicia penal más equitativa y más democrática. 
Como excepción a esta política criminal general, podemos citar una importante ley, la No 19.617 que modificó el Código Penal en materias relativas al delito de violación. Esta ley se inició a fines de 1993 y culminó como ley de la República en el segundo semestre de 1999.

En esta ley 19.617 se expresa una clara política criminal tendiente a fortalecer las sanciones en contra de aquellos que atentan contra la libertad sexual, mejorando los tipos penales para incluir situaciones que no estaban previstas en la antigua legislación penal.

Es decir, al patrocinar el Ejecutivo esta iniciativa dio una clara señal de política criminal en defensa de las víctimas de delitos sexuales.

En cuanto a posibles modificaciones procesales del sistema acusatorio, el discurso oficial del Ministerio de Justicia, fue que no debía efectuarse ninguna modificación de envergadura porque el sistema debía ser probado durante varios años después de su entrada en vigencia, política que se ha ido abandonando progresivamente en estos últimos años.

Respecto a la función que tendría el MP en materias de política criminal, la tendencia del Mensaje del Código Procesal Penal y del proyecto de Ley que creaba el Ministerio Público, según la política criminal del Ministerio de Justicia de fines de la década del '90, este organismo era un artífice importante en el diseño de las políticas criminales y estaba obligado el FN en su rendición de cuentas, a proponer modificaciones legales y políticas públicas de persecución penal.

Para el Mensaje del C.P.P. y del proyecto que culminó en la ley 19.519, que modificó la Constitución Política y en la ley 19.640, orgánica del MP, éste era un órgano importante en el diseño de las políticas criminales del país.

Para lograr este propósito, se proponía que el MP tuviera un gobierno colegiado dirigido por un Consejo Superior e integrado por representantes de los tres Poderes del Estado, que designaba al Fiscal Nacional, que estaba subordinado a este Consejo Superior.

Por ello es que dentro de sus funciones el Fiscal Nacional podía sugerir al Presidente de la República, a través del Ministerio correspondiente y escuchando previamente al Consejo Superior, las políticas públicas para el mejoramiento del sistema penal y las modificaciones legales para una efectiva persecución de los delitos. Ciertamente, la composición de este Consejo General directivo le daba autoridad al Fiscal Nacional para hacer proposiciones públicas de política criminal.

Sin embargo, la Comisión del Senado, y su criterio prevaleció en definitiva, consideró inconveniente que el FN propusiera políticas públicas penales, porque ello le correspondía al Ministerio de Justicia y que un uso inapropiado de esta atribución, crearía una situación incómoda para el Ejecutivo si no los compartiera o no pudiese aplicarlos, más aún si tales sugerencias pueden ser formuladas en cualquier oportunidad. 
Por ello, limitó la función sólo a la eventual sugerencia de modificaciones legales en la Cuenta Pública anual, "ya que no es adecuado que por ley se le encomiende proponer políticas públicas al Supremo Gobierno".

En lugar de formular políticas públicas, sólo se permitió al FN impartir criterios de actuación criminal a los fiscales en base a la legalidad existente, concepto bastante más limitado que la formulación de una política criminal para el Estado.

Esta situación duró hasta noviembre del año 2005 en que se dictó la ley 20.074, en que se reconoció como conveniente que en la cuenta pública el FN no solo propusiera modificaciones legales sino que también políticas públicas criminales.

En dicha ley, se modificó el artículo 21 de la ley 19.640, estableciéndose como obligación del Fiscal Nacional la proposición de políticas penales, en su Cuenta Pública anual, y ello se debió a una recomendación de la Comisión de Seguridad Ciudadana del Senado que elaboró un informe en que le parecía conveniente una mayor participación del MP en la formulación de políticas criminales, cambiando el criterio anterior.

Gran parte de las críticas al FN consistieron en que no formulara políticas públicas criminales y se abstuviera de incursionar en el campo preventivo del delito, olvidándose que las proposiciones del Ejecutivo en 1998 y 1999 sobre tales atribuciones al MP no habían sido acogidas por el Congreso Nacional. Esto es, las críticas partían del supuesto de que esta atribución del MP propuesta por el Ejecutivo de ese entonces, había sido acogido por el Congreso, situación que fue diametralmente opuesta.

A la injusticia de esta crítica, hay que agregar que el MP estaba recién organizándose, no estaba constituido en todo el país y no estaban designados todos sus fiscales regionales y adjuntos, y el temor que existía era que por dedicarse a tareas que no le competían legalmente, pudiera distraerse o desmejorarse la atención básica que establecía el Código para la investigación y sanción de los delitos o para la atención y protección de víctimas. $\mathrm{Al}$ respecto, debe considerarse que el MP partió de la nada y fue necesario organizar un servicio que no existía, resolviendo numerosas cuestiones prácticas de orden administrativo y económico que no estaban resueltas en la ley, a través de reglamentos, instrucciones y buenas prácticas.

Sin embargo y no obstante lo anterior, en los primeros años de la reforma (2000-2005) el MP nunca dejó de colaborar con las autoridades que tenían efectivamente la tuición directa de los temas relacionados con políticas criminales.

De otra parte, el nuevo sistema acusatorio debió implementarse gradualmente en el país y solo en el ańo 2005 se tuvo completa casi el 100\% de su dotación, al iniciarse la vigencia de la reforma en la Región Metropolitana.

No obstante lo anterior, en todas las cuentas públicas a contar del 2001, se propusieron modificaciones legales tanto al Código Penal y C.P.P. y hubo referencias a las distintas reformas que en los primeros años se habían aprobado para ajustar la reforma. 
Solo en las cuentas públicas del 2006 y del 2007, luego que la ley 20.074 de noviembre del 2005 modificara el Art. 21 de la ley del MP, para ampliar el objetivo de la cuenta pública con el fin de que también el FN pudiera proponer políticas públicas criminales al Supremo Gobierno, el MP pudo efectuar una serie de planteamientos de políticas criminales, parte de los cuales fueron acogidos posteriormente en la ley reciente 20.253 sobre agenda corta antidelincuencia, sin perjuicio de que otras modificaciones de la ley 20.074 habían sido sugeridas por el MP.

\section{B) Las politicas público-criminales durante los Ministerios de Justicia de los años 2000 a 2007.}

Se observa claramente que paulatinamente se abandona la posición tan absoluta del anterior Ministerio de Justicia (1994-1999) que desconfiaba de las modificaciones penales y procesales que se pretendieran hacer en el nuevo sistema de justicia penal.

Fueron numerosas las leyes que modificaron el Código Penal, el C.P.P. y la Ley del MP, en el período siguiente del 2000 al 2008.

Salvo error u omisión, el Código Penal ha tenido 25 modificaciones en este período, el Código Procesal Penal, alrededor de 13, la ley del Ministerio Público, más o menos 5 o 6 y el Código Orgánico de Tribunales, como 20 reformas.

Entre las más importantes al Código Procesal Penal podemos destacar:

B.1. La ley 19.789 de enero del 2002. El proyecto fue preparado en el Ministerio con la ayuda de algunos expertos y el apoyo de las Policías, para anular la sensación que tenía parte de la ciudadanía de que los delitos menores no eran perseguidos o quedaban impunes.

A esta ley le debemos que se estableciera que en determinadas faltas graves se pudiera detener al imputado, antes no se podía detener por faltas. Además, se legisló en materia de órdenes urgentes que podían ser expedidas verbalmente por los jueces de garantía, a petición de los fiscales; se perfeccionó el sistema de control de identidad, a petición de las Policías, para evitar su ineficacia.

Esta ley fue muy criticada por algunos académicos y en foros universitarios se la llamó como la ley hipócrita que abandonaba los postulados del primitivo Código Procesal Penal y las políticas criminales existentes al aprobar la reforma. Otros llamaron a esta ley y a otras posteriores, como la contrarreforma, pero pese a estas críticas estas modificaciones han sido prácticamente aprobadas por unanimidad en el Congreso Nacional.

B.2. La ley 19.806 , adecuatoria del sistema legal chileno al nuevo proceso penal, que modificó alrededor de 50 leyes y 5 códigos que tenían referencias al antiguo sistema inquisitivo penal. 
Si bien la tramitación de esta ley se había iniciado en la década del '90, luego se había abandonado su tramitación tras su aprobación en primer trámite, por estimar algunos de los personeros de la reforma que no era necesaria esta adecuación mediante ley, por estimar que el nuevo Código derogaba todas las leyes preexistentes que existieron en materia procesal penal y en la legislación orgánica de los tribunales, de modo que el sistema que ya había entrado en vigencia a fines del 2000, podía seguir funcionando sin las leyes adecuatorias.

Nos correspondió como Fiscal Nacional convencer al Ministerio de Justicia que la ley adecuatoria era absolutamente necesaria y enseguida explicar los alcances prácticos del tema en la Comisión de Legislación del Senado. Como el proyecto aprobado en la Cámara era muy insuficiente, el entonces Presidente de la Comisión del Senado y luego de mi exposición, se convenció de la necesidad de aprobar la ley adecuatoria, la que tuvo el No 19.806. De este modo se resolvieron numerosos vacíos legales y de interpretación que estaban provocando problemas en la aplicación del nuevo sistema.

La adecuación no pudo ser total porque existían referencias en la Constitución de 1980 que estaban referidas al antiguo proceso penal, problema que no pudo ser solucionado hasta la ley 20.050 que reformó la Constitución Política, aun cuando subsisten algunas referencias a la terminología del sistema antiguo.

Por lo demás no ha desaparecido el sistema antiguo, en el corto plazo de dos años que se habían previsto en las modificaciones del C.O.T. Al respecto, recuerdo haber pronosticado que había a lo menos 5 años de vigencia del sistema antiguo luego de entrar a regir el nuevo y el entonces Director de Investigaciones me rectificó y me dijo que serían 10. Con el trancurso del tiempo, el pronóstico de los diez años también ha sido equivocado porque hay centenares o miles de procesos pendientes en la justicia antigua.

Quizás, se eche de menos una legislación transitoria que acelere el pronto término de las causas del sistema antiguo a cargo de jueces del crimen y Ministros especiales, porque la desigualdad ante la ley que permitió con alguna razón el sistema gradual de implementación de la reforma, no puede perdurar en el tiempo ni pueden existir ciudadanos que gozan de un sistema público y acusatorio y otros que están sujetos a un sistema inquisitivo y semisecreto.

\section{B.3. Ley 20.074 de noviembre del 2005 que modificó el C.P.P. en materia de flagrancia, prisión preventiva, suspensión de la condena por simples delitos, abogado asistente, cooperación internacional, etc., y que favoreció la persecución penal de los fiscales y la intervención de las policías.}

En resumen y a vía de ejemplo, se aumentaron las hipótesis de flagrancia, se ampliaron las posibilidades de la prisión preventiva, se solucionó expresamente el tema de la declaración mediante circuito cerrado de televisión, se suprimió la suspensión de las condenas en los simples delitos, se estableció que el plazo de 24 horas del detenido se cumplía dejándolo bajo la custodia de Gendarmería del respetivo tribunal. 
B.4. La ley 20.253 sobre agenda corta antidelincuencia, de marzo del 2008 que aumentó los plazos que tiene la policía en el control de identidad, que estableció plazos en la flagrancia y no lo dejó a la libre apreciación de los jueces, que amplió las hipótesis del delito de receptación, que aumentó las plazas de los profesionales del MP (abogados asistentes y no fiscales), que hizo apelable la declaración de ilegalidad de la detención en los delitos graves, que permitió la apelación verbal de la negativa a la prisión preventiva en el caso de aquellos que hubieren sido puestos a disposición del tribunal en calidad de detenidos, etc. (Ver historia de la ley en "Agenda Corta Antidelincuencia" de Guillermo Piedrabuena Richard).

Estas modificaciones procesales, entre otras, se distanciaron claramente de los propósitos expresados reiteradamente en la segunda parte de la década del ' 90 , en el sentido de que no eran convenientes reformas parciales y que había que esperar bastantes años después de la vigencia de la reforma en todo el país, antes de empezar a meditar la conveniencia de cambios legales. El país no esperó, el Ejecutivo, el Congreso, las Policías y el propio Ministerio Público urgieron por algunos cambios que no eran estructurales y que se demostraban como necesarios en la aplicación del nuevo sistema de justicia penal. Nuevamente, existe un fenómeno muy interesante y que consiste en la separación de los conceptos de la academia de las concepciones generales de la sociedad y de quienes la representan.

Si este fenómeno se produjo en materia procesal penal, es aún mucho más evidente la ampliación del derecho penal ocurrida en estos últimos ocho años. A ella nos referiremos, en un capítulo siguiente.

C) Politica criminal de los Poderes Públicos en orden a aumentar los tipos penales para enfrentar riesgos, situaciones o problemas colectivos, estimándose que la solución penal es preferible a las sanciones meramente administrativas.

Entre los años 1998 a 2007, se dictaron numerosas leyes creando 119 nuevos tipos penales, los que pueden ser consultados en los anexos de la Cuenta Pública del Fiscal Nacional del año 2007. Lo anterior incluye las 25 leyes que modificaron el Código Penal, aproximadamente.

No pudiendo reproducirlos uno a uno, haremos mención solo de las principales leyes y delitos creados o modificados por esta legislación tan frondosa.

- $\quad$ Ley 19.617 de julio 1999, que modifica el C.P., C.P.P. y otros cuerpos legales en materias relativas al delito de violación.

- $\quad$ Ley 19.645 de 11.12.99, que modifica el C.P. en los delitos de corrupción. (Delito de trascendencia internacional).

- $\quad$ Ley 19.738 de 19.06.01, que modifica disposiciones penales del Código Tributario. 
- Ley 19.829 de 08.10.02, que modifica el Código Penal respecto del delito de cohecho.

- Ley 19.906 de 13.11.03, que modifica la ley 18.314 sobre conductas terroristas, de conformidad a lo dispuesto en la Convención Internacional para la represión de la financiación del terrorismo (igual a ley 19.645).

- Ley 19.913 de 18.02.03, que crea la Unidad de Análisis Financiero, creando diversos delitos. (Delitos de trascendencia internacional).

- Ley 19.927 de 14.01.04, que modifica el Código Penal en materia de delitos de pornografía infantil.

- Ley 19.947 de 17.05.04, sobre una nueva ley de matrimonio civil, creándose varios tipos penales.

- Ley 19.968 de 30.08.04, que crea los tribunales de familia y establece algunas disposiciones penales.

- Ley 19.974 de 02.10.04, sobre sistema de inteligencia del Estado, penándose la violación del deber de guardar secreto.

- Ley 19.975 de 06.10.04, que modifica el Código Penal en materia de uso y porte de armas.

- Ley 20.000 de 16.02.05, que sustituye la antigua ley No 19.366 que sanciona el tráfico ilícito de estupefacientes y sustancias psicotrópicas.

- Ley 20.009 de 01.04.05, que sanciona el uso fraudulento de tarjetas de crédito o débito.

- Ley 20.014 de 13.05.05, que modifica la ley No 17.798 sobre control de armas.

- Ley 20.066 de 07.10 .05 , sobre violencia intrafamiliar, en que se crean nuevas figuras penales tales como el delito de maltrato habitual.

Justamente esta semana se ha dado una charla en el Colegio de Abogados de un penalista, para tratar de los conflictos que se producen entre la ley de violencia intrafamiliar y el derecho penal. ¿¿Se tratará del mismo conflicto entre los que sostienen el derecho penal mínimo y los que persiguen ampliar el derecho penal para resguardar peligros, riesgos y situaciones que no pueden ser resueltos por otras ramas del derecho?

- Ley 20.074 sobre delitos de falso testimonio y obstrucción de la justicia.

- Ley 20.088 de 05.01 .06, sobre declaración patrimonial obligatoria de los funcionarios que ejercen una función pública, que sanciona al que durante el ejercicio de su cargo obtenga un incremento patrimonial relevante. ¿Y qué se entenderá por incremento relevante? ¿Es esta una ley penal en blanco o de una tipicidad demasiado amplia que puede afectar indebidamente a las autoridades públicas? 
- Ley 20.090 de 11.01.06, que sanciona con mayor vigor el abigeato y facilita su investigación.

- Ley 20.120 de 22.09.06, que prohíbe la clonación humana, penalizando ciertas conductas.

- Ley 20.162 de 09.01.07, que establece modificaciones a la ley 14.908 sobre abandono de familia y pagos de pensiones alimenticias, sancionando o penalizando diversas acciones del demandado o del que oculte las fuentes de ingreso del demandado.

- Ley 20.253 sobre receptación y modificación reincidencia.

- Ley 20.140 de 30.12.06, que modificó el Art. 494 bis, en los hurtos de pequeño monto (¿delitos de bagatela?).

Estas son leyes que se refieren a los hurtos cometidos en supermercados, incluyendo los de escaso valor, para enfrentar redes organizadas de personas que desvalijan los establecimientos ocultando especies de poco valor. ¿Es esta una demostración de una nueva política criminal contradiciendo la anterior que rechazaba la persecución de los delitos de bagatela como lo expresó el proyecto de Mensaje del nuevo C.P.P.?

Debe recordarse además que en la década del '90, se dictó una legislación que entregaba a la competencia de los juzgados de policía local los hurtos de escaso valor, política que no dio resultado.

A lo anterior hay que agregar las leyes que castigaron las lesiones y/o agresiones que sufrieran las policías, los gendarmes y los fiscales del Ministerio Público.

Por último, hay numerosos proyectos que se encuentran pendientes en el Congreso Nacional sobre las más variadas materias, tales como delitos de la propiedad intelectual, comercio ilegal, medio ambiente, nuevos delitos informáticos, modificación de los delitos de lavado de dinero, etc.

Esta proliferación legislativa se ha dado no obstante ciertos anuncios de que se impulsaría un nuevo Código Penal, habiéndose entregado un proyecto al Ministerio de Justicia, en que se reformularía el derecho penal chileno, eliminándose todos los delitos especiales contenidos en leyes varias y entiendo que también eliminándose las faltas penales.

En definitiva, no se advierte una política criminal clara de los órganos pertinentes del Estado y se está a las necesidades y desafíos que van surgiendo de la complejidad de la actual sociedad.

Nadie se pregunta o analiza si el sistema penal da abasto para conocer eficazmente los cientos de delitos que se crean y si los actores del nuevo proceso, sean jueces, fiscales o defensores, están capacitados o si deben capacitarse para que esta nueva competencia sea ejercitada de manera eficiente y si se otorgan recursos al sistema. 
Como botón de muestra, la ley 20.066 que creó el delito del maltrato habitual, rubro que constituye el segundo ingreso más importante de esta ley y en que el número de denuncias es considerable, no creó nuevos fiscales o jueces, y a su vez la ley 20.084, con un nuevo sistema de responsabilidad de los adolescentes por infracciones a la ley penal, incorporando un universo considerable de menores entre 14 y 16 años, tampoco contempla un número suficiente de fiscales y de tribunales especializados sobre el tema y recursos para el Sename.

D) Políticas públicas propuestas por el Fiscal Nacional del MP, en sus cuentas públicas anuales de los años 2006 y 2007, luego de la modificación del Art. 21 de la ley 19.640 introducida por la ley 20.074. Cuenta Pública del 2006.

\section{Políticas Públicas para el Mejoramiento del Sistema Penal}

La ley 20.074 modificó el artículo 21 de la ley 19.640, orgánica del Ministerio Público estableciendo que el Fiscal Nacional en su cuenta pública podrá "sugerir las políticas públicas y modificaciones legales que estime necesarias para el mejoramiento del sistema penal, para una efectiva persecución de los delitos, la protección de las víctimas y de los testigos y el adecuado resguardo del derecho de las personas".

Esta modificación legal viene a recoger una de las recomendaciones formuladas por la Comisión de Expertos, que en el año 2003 sugirió diversos ajustes a la reforma procesal penal y las de la Comisión de Seguridad del Senado del 2005 en el mismo sentido.

Esta decisión legislativa importa un explícito reconocimiento a la institución Ministerio Público: seis ańos después de comenzar a regir el nuevo régimen procesal penal en el país, con el Ministerio Público como gran protagonista, los Poderes legisladores reconocen en él al órgano estatal más capacitado y experimentado en la problemática penal, lo que explica que echando pie atrás en su decisión originaria, por la que se negó a este Ministerio la posibilidad de formular políticas públicas, hoy, en cambio, le autoricen expresamente para proponerlas.

Si bien el Ministerio Público elabora y ejecuta políticas propias de persecución penal, su misión hoy debe complementarse mediante propuestas que mejoren la actividad estatal de otros sujetos que intervienen en el proceso penal. (Policías, servicios auxiliares, Gendarmería, etc.)

Estas propuestas podrán comprender tanto la actividad que se estime social, jurídica y políticamente necesaria para el mejor cumplimiento de la función preventiva que se confiere al sistema, como a la represiva y ejecutiva: ello importa formular proposiciones de desempeño de órganos estatales diversos que no dependen del MP. 
Con esta nueva facultad no se ha alterado el rol institucional del Ministerio Público para transformarlo en un órgano omnipoderoso, sino que se le invita a opinar sobre los modos y posibilidades concretas de perfeccionar el sistema penal, sea proponiendo que se legisle, sea induciendo a la adopción o erradicación de prácticas, sea exhortando a desempeñar, conjunta o separadamente, determinados comportamientos necesarios.

Habrá que atender, ciertamente, a temas preventivos, aludiendo a tópicos usualmente fuera del estricto debate jurídico penal, como pueden ser temas de desarrollo social, educacional y esparcimiento; también a algunos estrechamente vinculados con la actividad persecutora, como el de selección, capacitación y promoción policial.

Naturalmente, habrá que guardar una línea de prudencia y a veces hasta de reserva para evitar polémicas con organismos del Estado. También el Ministerio Público debe evitar verse envuelto en controversias políticas ajenas a su naturaleza. La autonomía constitucional, privilegio indispensable para un desempeño libre e independiente, impone una considerable cuota de responsabilidad.

En resumen, el encargo legal otorga un apasionante y exigente nuevo desafío para el Ministerio Público, en cumplimiento del cual deberá desarrollar destrezas nuevas que le permitan plantearse con rigor y objetividad sobre los problemas del sistema penal, entendiendo que se incursiona en un terreno que si bien es abonado por la dogmática jurídica es, antes que nada, esencialmente político, y por tanto, se trata de temas no sólo opinables sino, inevitablemente, objetos de crítica política.

En consecuencia, dada la reforma al artículo 21 de la ley 19.640, Orgánica Constitucional del Ministerio Público, no solo en la cuenta pública anual sino que además cada vez que las circunstancias lo exijan, deberá el Fiscal Nacional aprovechar la oportunidad de superar el aislacionismo que representa la autonomía constitucional, para sugerir la adopción de políticas públicas pertinentes a la solución de cuestiones de trascendencia para el sistema penal.

La Fiscalía Nacional formó una Comisión para tratar el tema de las políticas públicas que se sugerirían para mejorar el sistema penal, empezando por delinear el fundamento y límite de la nueva atribución del Ministerio Público.

Esta Comisión escuchó la opinión de académicos de varias Universidades del país, de CEJA y de la Fundación Paz Ciudadana.

En el debate se sugirieron varias propuestas, entre las cuales se sugieren las propuestas concretas siguientes:

1. En cuanto al mejoramiento del sistema procesal penal, perfeccionar la salida alternativa de la suspensión condicional del procedimiento, a través de mecanismos legales y reglamentarios que beneficien el control del cumplimiento de las condiciones fijadas y la reinserción laboral del imputado, contribuyendo de esta manera a su efectiva rehabilitación e impidiendo que vuelva a incurrir en hechos 
presumiblemente delictuosos (Esta la experiencia de los tribunales o Cortes de drogas).

2. Mejorar el sistema legal de control de las medidas cautelares y el cumplimiento alternativo de penas privativas de libertad.

Hay que efectuar todas las modificaciones legales y reglamentarias para mejorar significativamente el control de las personas sujetas a medidas cautelares que importan un cierto grado de libertad (tales como permiso de salida durante el día en el caso de la prisión preventiva, arresto domiciliario, prohibición de frecuentar ciertos lugares, etc.) o de cumplimiento alternativo de penas privativas de libertad (remisión condicional, reclusión nocturna o libertad vigilada), e incluso de las actividades que realizan los condenados al interior de los establecimientos penales.

3. Cumplimiento efectivo de la pena de multa.

Es necesario controlar su cumplimiento efectivo de forma tal que si el condenado carece de medios para pagarla, sea conmutada por la realización de trabajos en beneficio de la comunidad. Para ello, se requiere de una infraestructura apropiada que, junto con permitir el efectivo cumplimiento, revista de seriedad la amenaza penal asociada a toda conducta ilícita.

4. Apoyo del Ministerio Público a la generación de una red social que funcione coordinadamente con organismos públicos y privados para ofrecer capacitación laboral, tanto bajo la suspensión condicional como bajo la ley 18.216.

El desarrollo técnico de esta política demandará inversiones y recursos destinados a la reinserción laboral y a la construcción de una red de coordinación entre organismos públicos y privados que apoyen la rehabilitación del beneficiado.

Esta sugerencia de política pública ha sido seguida por el Ministerio de Justicia, enviando el proyecto a que se ha hecho referencia anteriormente (Boletín No 5838-07).

5. En cuanto a las medidas para una más efectiva persecución de los delitos, se propone fomentar la transferencia de información, con ayuda de medios tecnológicos, entre los sistemas informáticos de las policías y el Ministerio Público, y el acceso a las bases de datos y bancos de imágenes públicas y privadas (Policía, Registro Civil, Gendarmería, grandes tiendas, supermercados, etc.). También, el proyecto de ley (Boletín 5838-07) y la disposición del Art. $3^{\circ}$ permanente de la ley 20.253 sobre agenda corta antidelincuencia en lo que se refiere a la base de datos unificada de las policías, responden a esta propuesta de política pública sugerida por el MP.

6. Potenciamiento y actualización de las cámaras de vigilancia en los espacios públicos, por parte de las municipalidades e intendencias y su inserción dentro de las estrategias antidelictuales coordinadas entre el Ministerio Público y las policías. 
7. Potenciamiento de la capacidad para interceptación telefónica y registro de tráficos telefónicos, tanto en las compañías de teléfonos como en las policías.

8. Intensificación de campańas mediáticas destinadas a difundir hábitos y mejores prácticas de prevención del delito.

Estas campańas deben cambiar malos hábitos fuertemente arraigados en la población, tales como el robo en supermercados y tiendas de autoservicio o la conducción en estado de ebriedad o bajo la influencia del alcohol o drogas, o la compra de artículos de procedencia ilícita, tanto por la vía de mostrar los efectos indeseados que tales conductas puedan acarrear a los propios hechores como también del llamado dirigido a quienes sean testigos de la comisión de esos delitos para que los denuncien sin temor.

9. Generar instancias de coordinación entre el Ministerio Público, el Gobierno, las Policías, las municipalidades y el sector privado con la finalidad de individualizar, mediante mapas, los mercados de reducción de especies robadas y diseñar estrategias de intervención de dichos mercados.

De esta manera, los fiscales podrán perseguir decididamente el delito de receptación, extendiendo su acción a los mercados ilícitos de reducción de especies.

10. Apoyar la creación del Ministerio de Seguridad Pública, a fin de que se realice adecuadamente una coordinación de ambas policías y de todos los organismos del Estado, en materias de prevención del delito, sin perjuicio de la coordinación con las labores investigativas y el ejercicio de la acción que realiza en forma autónoma el Ministerio Público.

El Ministerio Público observa con preocupación, tal como lo señaló la Comisión de Seguridad Pública del Senado, cierta descoordinación de los organismos del Estado en materia de prevención y represión del delito y una falta de políticas públicas que dirijan la acción del Estado en el combate del delito y respeto de los derechos de las personas, en especial de las víctimas.

La autonomía constitucional del Ministerio Público para dirigir en forma exclusiva la investigación y sostener el ejercicio de la acción penal, no es obstáculo para la colaboración recíproca entre nuestro organismo y el Ministerio de Seguridad Pública, respetándose los roles que cada uno tendrá asignados en la ley.

Finalmente, concordamos con la recomendación de la Comisión de Seguridad Ciudadana del Senado, que es indispensable un mayor grado de coordinación entre el Ministerio Público y el Ejecutivo, y por ello es menester otorgar a nuestro organismo facultades para intervenir en el diseño de políticas públicas de seguridad ciudadana, cumpliendo un rol más activo en esta materia con el Gobierno y demás instituciones relacionadas. 


\section{La Seguridad Pública y el Ministerio Público}

La preocupación por la seguridad pública es un tema ineludible para nuestra institución, tema sobre el cual nos referimos extensamente en nuestra última cuenta pública.

La naturaleza de organismo autónomo del Ministerio Público no puede ni debe importar un aislacionismo perjudicial a la marcha del Estado y a los intereses de la sociedad.

En este contexto, nuestro organismo está participando activamente en distintos frentes relacionados con el tema de la seguridad pública y la prevención del delito. Así, colabora en las Comisiones Regionales de Seguridad, en las Comisiones Nacionales dirigidas por el Ministerio del Interior y aspira a integrar el Consejo de Seguridad Pública si se crea en el proyecto de ley respectivo. También nuestros fiscales han participado activamente con juntas de vecinos, alcaldes y organismos comunitarios, en iniciativas para prevenir la delincuencia y proteger a los ciudadanos.

Además, los fiscales han hecho un muy valioso aporte a la seguridad pública mediante su oportuna e inteligente persecución penal y existe una clara sensación en la opinión pública de que actuamos responsablemente en los delitos graves, con las herramientas que el ordenamiento nos otorga.

Hemos propuesto numerosas medidas de mejoramiento de las políticas criminales de prevención y persecución penal, que si bien han sido comunicadas a los Poderes Públicos, aún no tienen respuesta.

Desde luego, reiteramos nuestro interés en que se active el proyecto sobre creación del Ministerio de Seguridad Pública o de la Subsecretaría respectiva que va a liderar las iniciativas para mejorar la seguridad pública, tareas a las que colaborará decididamente el MP.

Primitivamente, el MP estimó que era preferible un Ministerio especial a cargo de la seguridad pública y así lo informó al Ejecutivo. Posteriormente, ha existido otra opción política que consiste en la creación de una subsecretaría de prevención y seguridad, por lo que el proyecto fue modificado. El inconveniente de la subsecretaría es que muchos de los temas de seguridad ciudadana dependen de otros Ministerios ajenos al de Interior, como los aspectos penitenciarios, la estabilidad laboral, la protección de la familia, los beneficios de la ley 18.216, la labor del Sename, del Sernam, del Registro Civil, etc., etc.

Otra proposición en la que es urgente insistir para que los Poderes del Estado puedan enfrentar la creciente criminalidad en los robos violentos, tráficos de drogas, delitos contra las personas, es aquella se relaciona con la configuración de un nuevo delito de receptación de las especies adquiridas ilícitamente, sin perjuicio de las medidas administrativas y policiales que son necesarias para complementar el delito de receptación. Esta nueva configuración de delito se aprobó en la ley 20.253 de Agenda Corta Antidelincuencia, pero obviamente necesita un replanteamiento porque los delitos 
de robo, hurto o apropiación no podrían efectuarse si los hechores no tuvieran un mercado seguro para la venta de las especies ilícitas. La modificación fue muy suave y no tendrá mayores repercusiones por la baja cuantía de la pena y porque se exige una especie de dolo directo y un conocimiento, a veces difícil de probar, de que las especies adquiridas tienen un origen ilícito.

Especialmente grave es la receptación de los alambres y elementos de cobre que se sustraen a gran escala para exportarlos fuera del país aprovechando el alto precio del cobre y produciendo un gran perjuicio a la marcha de la economía y dejando en la penumbra a extensas zonas de nuestras ciudades. El proyecto, se despachó totalmente por el Congreso, en fecha reciente, y está en condiciones de ser ley. Es evidente que una política criminal más enérgica respecto del robo de cables, será ampliamente apoyada por todos los sectores.

La Fiscalía Nacional preparó un plan estratégico contra la receptación de vehículos robados o de piezas producto de robos o hurtos de dichos vehículos, que ha sido enviado al Ministerio del Interior en meses pasados, a la espera de que sea considerado por el Poder Ejecutivo porque requiere de la colaboración de organismos administrativos y policiales que no dependen de nuestra Institución.

El MP carece de iniciativa y facultad legal para promover modificaciones que fortalezcan la seguridad pública y en general no tiene poder coactivo sobre la ejecución de las políticas criminales de prevención del delito. Tampoco tiene potestad reglamentaria que obligue a otros servicios de la Administración del Estado.

Finalmente, existe un tema estratégico que debe ser resuelto próximamente, sea en el proyecto que crea el Ministerio de SP como en la ley que corresponda. Si bien el MP puede proponer políticas criminales, ¿cuál es la autoridad que decide cuáles son estas políticas y cómo se ejecutan? ¿Es el nuevo Ministerio, a través de la Subsecretaría correspondiente? ¿Es el Ministerio de Justicia? ¿Es el Congreso Nacional? ¿Es el propio Presidente de la República quien debe fijar anualmente una política criminal moderna, respetuosa de los derechos y que sea eficiente? ¿Tiene alguna intervención el Poder Judicial o es efectivo que el tema de la seguridad pública no tiene ningún interés ni podría tenerlo para los tribunales?

¿Podría ser el Ministerio de Justicia que siempre fue considerado como el órgano del Ejecutivo que velaba por la juridicidad del sistema legal chileno y que tenía la iniciativa para proponer al Presidente de la República las políticas legales que debían seguirse y que pudieran anunciarse al país a lo menos una vez al año en el Mensaje Presidencial?

¿O va a ser la nueva Subsecretaría de Seguridad Pública dependiente del Ministro del Interior, en circunstancia de que existen varios Ministerios a cargo de políticas sectoriales que influyen en las políticas criminales, tales como el Ministerio de Justicia (tratamiento penitenciario, de los menores) o como el Ministerio de Vivienda, de Salud, del Trabajo, etc., o de organismos tan importantes como el Conace y otros? 
¿Le corresponderá al Congreso la formulación de políticas criminales? Más bien se ve como un órgano que fiscaliza, que propone y que legisla sobre modificaciones legales de iniciativa del Gobierno, pero también a veces de los propios parlamentarios.

¿Y el Poder Judicial? Tradicionalmente la respuesta ha sido que los jueces están para juzgar los casos concretos sometidos a su conocimiento, pero nada tienen que hacer ni proponer en materia de políticas criminales porque ello le incumbe al resto de los Poderes del Estado.

No estamos tan seguros de estar de acuerdo con esta respuesta tan categórica y habría que debatirla en seminarios o jornadas. ¿̨or qué sería inconducente que el Presidente de la Corte Suprema en su Cuenta Pública anual pudiera sugerir, al igual que el Fiscal Nacional, modificaciones importantes a la legislación penal y procesal, en circunstancia de que la opinión de la Corte Suprema debe ser escuchada tratándose de leyes orgánicas que se relacionan con la Administración de justicia? En el hecho, en reuniones privadas siempre los jueces han manifestado su opinión y también lo han hecho en la Comisión Coordinadora de la Reforma Procesal Penal. Limitar a los jueces a una función pasiva de observar y no opinar sobre temas trascendentales de la justicia, parece que no se ajusta a los padrones de una sociedad moderna.

¿Y el Ministerio Público? Ya me referí a la evolución legal del tema en la ley 19.640. Es positivo que continúe formulando proposiciones de política criminal, incluyendo modificaciones al Código Penal o al Código Procesal Penal o a las leyes que sean necesarias. Un punto dudoso es que si los Poderes Públicos, en especial el Ejecutivo, no escucha ni le parece interesante el punto de vista del MP, el Fiscal Nacional queda en una posición incómoda. El otro punto es que siempre que el MP colabore con el Ejecutivo en las tareas de la seguridad pública, debe hacerlo de una manera independiente y autónoma, evitando su utilización política; no necesitamos dar ejemplos al respecto.

Entendemos además que el MP puede manifestar su opinión sobre políticas públicas no solo en la cuenta pública anual (Art. 21 no excluye otras oportunidades) sino que en cualquier oportunidad, aunque la cuenta pública es la vía más solemne y más conocida.

Estas incógnitas están parcialmente resueltas en las líneas anteriores, pero sería muy conveniente que las conversáramos entre todos.

Finalmente, está el interesante y complejo tema de las víctimas, su atención, protección y defensa, dentro de la política criminal de un Estado, junto con un proyecto reciente del Ministerio de Justicia creando un fondo nacional de ayuda a las víctimas de pocos recursos para que ejerzan sus derechos en el nuevo proceso penal. 